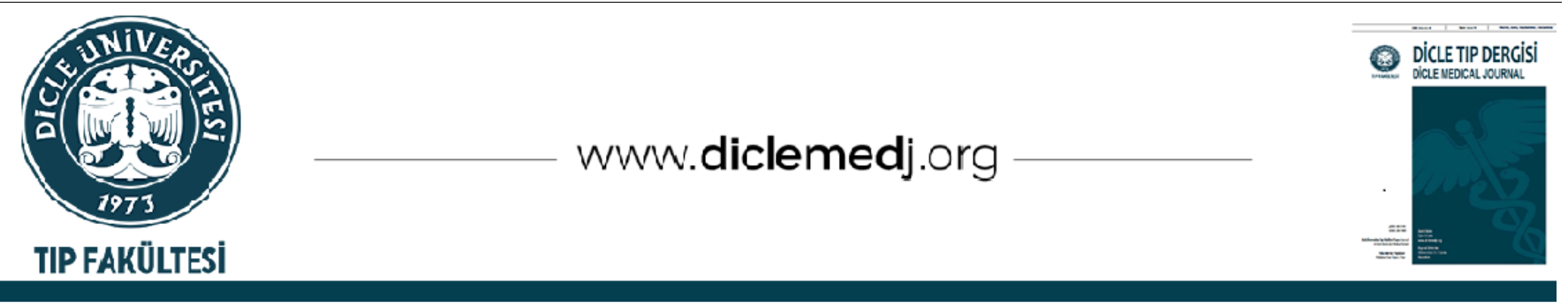

\title{
Sigara İçiminin Gastrik Miyoelektrik Aktiviteye Etkisinin Araştırılması
}

\author{
Hamza Kaya ${ }_{1}$, Hüda Oflazoğlu Diken ${ }_{1}$, Hacer Kayhan Kaya iD 1, Mustafa Kelle iD $_{1}$, Cemre Uçar Ekin ${ }_{1}$ \\ 1 Dicle Üniversitesi Tıp Fakültesi Fizyoloji Anabilim Dalı Diyarbakır, Türkiye
}

Geliş: 14.07.2021; Revizyon: 07.10.2021; Kabul Tarihi: 26.10.2021

$\ddot{0} \mathbf{z}$

Amaç: Sigara içimi gastrointestinal sistem dahil olmak üzere bir çok doku, organ ve sistemi etkilediği bilinmektedir. Mide motor fonksiyon bozukluklarının bazı belirti ve semptomlarının, elektrogastrografik analiz sonuçlarıyla iyi korelasyon gösterdiği ifade edilmiştir. Şu ana kadar sigaranın mide hareketlerini yöneten gastrik miyoelektrik aktiviteye etkileri konusunda sınırlı sayıda çalışma yapılmıştır. Bu çalışmada, elektrogastrografi (EGG) tekniğinden yararlanılarak sigara içiminin gastrik miyoelektriksel aktiviteye etkisinin incelenmesi amaçlandı.

Yöntemler: Çalışma 8'i sigara içen ve 7'si sigara içmeyen 25-40 yaş aralığında ve bilinen gastrointestinal sistem dahil herhangi bir rahatsızlığı bulunmayan toplam 15 sağlıklı ve gönüllü erkek birey üzerinde gerçekleștirildi. Her katılımcı için 30 dakikalık kontrol periyodu ve ardından 60 dakikalık deney periyodu abdominal EGG kaydı alındı. Tüm kayıtlar aç karna, aynı gün içinde ve ardışık olarak kaydedildi. Günde en fazla iki bireyin kaydı yapıldı. EGG kayıtlarındaki normogastri yüzdesi, dominant frekans ve dominant güç parametrelerini gösteren dalgalar; spektral analiz programı kullanılarak analiz edildi. Kontrol periyodunda kronik sigara içiminin, deney periyodunda ise kronik içicilerde akut sigara içiminin etkisi araştırıldı. Çalışmadan elde edilen verilerin değerlendirilmesinde nonparametrik testlerden MannWhitney U testi kullanıldı. Karşılaştırmalardan elde edilen p değerleri $\mathrm{p}<0.05$ ise anlamlı olarak değerlendirildi.

Bulgular: Kontrol periyodunda kronik sigara içen bireylerin EGG kaydı sonuçları sigara içmeyen bireylerin sonuçlarıyla karşılaştırıldığında sigara içenlerde normogastri yüzdesi, dominant frekans ve dominant güç parametrelerinin her üçünde anlamlı olmayan bir azalma saptandı. Ancak, deney periyodunda kronik içicilerde akut sigara içiminin hem normogastri yüzdesini hem de dominant güç değerini anlamlı olarak azalttığı belirlendi.

Sonuç: Çalışmadan elde edilen sonuçlar, sigara içiminin özellikle aktif - akut sigara içiminin gastrik miyoelektriksel aktiviteyi azalttığını göstermiştir.

Anahtar kelimeler: Elektrogastrografi, sigara, gastrik miyoelektrik aktivite

DOI: 10.5798/dicletip.1037801

Yazışma Adresi / Correspondence: Hüda Oflazoğlu Diken, Dicle Üniversitesi Tıp Fakültesi Fizyoloji Anabilim Dalı Diyarbakır, Türkiye e-mail: hudad@dicle.edu.tr 


\title{
The Effect of Smoking on Gastric Myoelectrical Activity
}

\begin{abstract}
Objective: It is known that smoking affects many tissues, organs, and systems, including the gastrointestinal system. It has been stated that some signs and symptoms of gastric motor dysfunctions correlate well with electrogastrographic analysis results. Limited studies have been conducted on the effects of smoking on gastric myoelectrical activity, which governs gastric movements. This study aims at investigating the effects of smoking on gastric myoelectrical activity by using electrogastrography (EGG) technique.
\end{abstract}

Methods: The study was carried out on 15 male volunteers, 8 of whom were smokers and 7 of whom were non-smokers. The participants were aged between 25 and 40 and they had no previously diagnosed diseases, including the gastrointestinal tract. Abdominal EGG recordings were taken for each participant during a 30-minute control period and a 60-minute experimental period consecutively. All records were recorded on an empty stomach, at the same day. A maximum of two individuals were examined per day. Waves showing the percentage of normogastria, dominant frequency and dominant power parameters in EGG recordings were analysed using a spectral analysis program. In the control period the effects of chronic smoking and in the experimental period the effects of acute smoking in chronic smokers were investigated. Mann-Whitney U test, one of the nonparametric tests, was used to evaluate the data obtained from the study. The $\mathrm{p}$ values obtained from the comparisons were considered significant if the $\mathrm{p}<0.05$.

Results: When the EGG results of chronic smokers in the control period were compared with those of non-smokers, a non-significant decrease was found in all three parameters of smokers namely percentage of normogastria, dominant frequency and dominant power. However, it was determined that acute smoking in chronic smokers significantly decreased both the percentage of normogastria and the dominant power value during the experimental period.

Conclusion: The results obtained from the study showed that smoking, especially active- acute smoking, reduces gastric myoelectrical activity.

Keywords: Electrogastrography, smoking, gastric myoelectrical activity.

\section{GíRiş}

Mide hareketlerinin düzenlenmesinde gastrik miyoelektrik aktivite (GMA) önemli rol oynar. Mide miyoelektrik aktivitesi, gastrik yavaş dalgalardan ve bu dalgalar üzerinde şekillenen ani - dikensi potansiyellerden oluşur. Gastrik yavaş dalgalar, gastrik kasılmaların sıklığını ve yayılmasını belirlerken, dikensi potansiyeller antral kasılmaları başlatır. Dakikada ortalama 3 döngü (Cycle Per Minute, cpm) ritminde oluşan midenin yavaş dalgaları, gastrik korpusun proksimalinde büyük kruvatur üzerinde bulunan pacemaker hücreler tarafından üretilir. Yavaş dalga frekansı türe özgü olarak değişkenlik gösterir. İnsanlarda 2 - $4 \mathrm{cpm}$ dir. Yavaş dalga frekansı $<2 \mathrm{cpm}$ ise bradigastri, > $4 \mathrm{cpm}$ ise taşigastri ve spektrumda baskın bir pik gücü yoksa aritmi olarak isimlendirilir ${ }^{1}$.

Elektrogastrografi (EGG), mide miyoelektrik aktivitesinin kaydı ve analizinde kullanılan maliyeti düşük, uygulaması kolay ve invazif olmayan bir tanı yöntemidir ${ }^{1}$. EGG kaydındaki yavaş dalga anormalliklerinin gastrik hipomotilite ile ilişkili olduğu ve gecikmiş mide boşalmasını öngördüğü bildirilmiştir. Mide disfonksiyonuna ait belirti ve semptomların elektrogastrografik kayıt ve gastrik miyoelektrik aktivite analiz sonuçlarıla uyumlu olduğu gösterilmiștir².

Sigara dumanındaki kimyasalların başta akciğerler olmak üzere birçok organ ve dokularda zararlı etkilerinin olduğu, gastrointestinal kanalın salgı ve hareket fonksiyonunda bozukluğa neden olduğu gösterilmiştir ${ }^{3-5}$. Son zamanlarda mide-barsak motilite bozukluğunun birçok gastrointestinal hastalığın patogenezinde önemli rol oynayabileceği ve hastalı̆̆ın iyileşme sürecini geciktirebileceği belirtilmiştir ${ }^{6}$. Nikotin, tütünün temel aktif bileşenidir ve nikotine 
maruz kalma sigara içimiyle eşdeğer kabul edilir. Sigara içen kişilerde mide sıvısındaki nikotin miktarı kandaki düzeyine göre oldukça yüksek bulunmuştur ${ }^{7}$. Sigara içimi veya nikotin uygulamasının gastrik motor fonksiyonları yavaşlattığı veya bozduğuna dair genel bir görüş olmasına rağmen ${ }^{8-10}$, mide motor işlevlerini etkilemediği ${ }^{11}$ veya hızlandırdığına dair araştırma sonuçları da bulunmaktadır ${ }^{12,13}$. Ancak, sigara içimi veya nikotin uygulamasının insan mide miyoelektrik aktivitesine etkileri konusunda çok az sayıda çalışma yapılmıştır ${ }^{14}$.

Sigara içimi veya nikotin uygulamasının mide hareketlerine etkileri konusunda çok sayıda araştırma yapılmış ve çelişkili sonuçlar bildirilmiştir. Ancak, mide motilitesini yöneten gastrik miyoelektrik aktivite üzerine sigaranın etkilerini elektrogastrografi tekniği ile inceleyen çalışma bulunmamaktadır. $\mathrm{Bu}$ çalışmanın amacl; EGG tekniğinden yararlanarak sigaranın gastrik miyoelektrik aktiviteye etkisini araştırmaktır.

\section{YÖNTEMLER}

\section{Çalışmaya \\ Alınan Belirlenmesi}

Bu çalışma 7'si sigara içmeyen (daha önce hiç sigara içmemiş) ve 8'i sigara içen (en az 5 yıldır günde bir paket ve fazlası sigara içen) 25-40 yaş aralığında ve bilinen gastrointestinal sistem dahil herhangi bir rahatsızlığ bulunmayan toplam 15 sağlıklı ve gönüllü erkek birey üzerinde gerçekleștirildi. Çalışma öncesinde Dicle Üniversitesi Tip Fakültesi Girişimsel Olmayan Klinik Araştırmalar Etik Kurulu komitesinin 03.06.2021 tarihli 303 numaralı kararı ile çalışma için etik kurul onayı alındı. Ayrıca çalışmaya dahil edilen tüm katılımcılara "Bilgilendirilmiş Gönüllü Olur Formu" ile yapılacaklar hakkında bilgi verildi ve gönüllü olduklarına ilişkin imzaları ile izinleri alındı. Katılımcıların boy (m) ve kiloları $(\mathrm{kg})$ ölçülerek $\mathrm{kg} / \mathrm{m}^{2}$ cinsinden BMI değerleri hesaplandı.

\section{Deney Protokolü}

Tüm katılımcıların EGG kayıtları Anabilim Dalımız Araştırma Laboratuvarında gerçekleştirildi. Sigara içen bireylere kayıt gününden önceki son 24 saatte sigara içmemeleri gerektiği tembih edildi. En az 8-12 saatlik açlıktan sonra sabah saat 09:00 civarında laboratuvara gelen gönüllü bireylerin birkaç dakika dinlenmeleri sağlandıktan sonra EGG çekimlerine başlandı. Çekimler için EGG MP 150 sistem kullanıldı (EGG MP 150 system, Biopac inc. Santa Barbara, CA, USA). Çekim için sessiz bir ortam sağlandı ve katılımcıların sedye üzerinde hareketsiz bir şekilde yatar pozisyonda kalmaları, çekim süresince konuşmamaları, derin nefes almamaları, mümkün ise uyumamaları tembih edildi. Ardından abdominal deriye üç yüzeyel elektrot şu şekilde yerleștirildi. İki aktif elektrot epigastrik bölgede olmak üzere biri ksifoid ile göbek arası orta noktaya, diğeri ilk yerleştirilen elektrodun $5 \mathrm{~cm}$ solu ve bu noktanin $5 \mathrm{~cm}$ yukarısına $\left(45^{\circ}\right.$ açı ile) yerleştirildi. Referans olarak kullanılan üçüncü elektrod ise bireyin sağ tarafında olmak üzere ilk yerleştirilen elektrodtan 10-15 cm mesafede ve aynı seviyede yerleştirildi ${ }^{15}$. EGG sinyalleri portatif bir EGG rekorder kullanılarak amplifiye edildi (Digitrapper EGG, Synectics Medical AB, SynecticsMedical Inc, Irving, TX).

Her bireye ait EGG kaydında ilk olarak 30 dakikalık kontrol periyodu EGG çekimi gerçekleştirildi. Bu çekimin hemen ardından sigara içen bireyler sedye üzerinden kalkmadan, aynı pozisyonda üst üste iki sigarayı (Camel $1 \mathrm{mg}$ nikotin/sigara) içmek suretiyle, sigara içmeyen bireyler ise ağızlarında yanmayan sigara bulundurmak suretiyle (taklit sigara içimi) her bireyin 60 dakikalı deney periyodu EGG çekimi yapıldı. Tüm veriler, Fast Fourier tabanl (FFT) ve spektral analizleri çalıştıran bilgisayar yazılımı kullanılarak otomatik olarak analiz edildi. 
EGG Kaydında Değerlendirilen Parametreler Gastrik miyoelektrik aktivitenin belirlenmesinde kullanılan parametreler şu şekildedir.

Normal Yavaş Dalgaların Yüzdesi (Normogastri \%'si): EGG kaydı boyunca 2-4 cpm aralığındaki gastrik yavaş dalgaların \% değerini temsil eder.

Dominant Frekansı (Dominant Frequency, DF): Bir EGG kaydında güç spektrumunun 0,5-9,0 cpm aralığında bir tepe güce sahip olduğu frekanstır.

Dominant Güç (Dominant Power, DP): EGG spektrumundaki Dominant frekanstaki güç, EGG Dominant gücü olarak tanımlanır.

\section{İstatistiksel Analiz}

Çalışmadan elde edilen verilerin değerlendirilmesinde, iki bağımsız grubun ortalamalarını karşılaştırmak için kullanılan nonparametrik testlerden Mann-Whitney U testi kullanıldı. Her bir parametreye ait değerler ortalama \pm SD şeklinde verildi. İstatistiksel incelemeler güncel SPSS (18. versiyon) programı yüklenmiş bilgisayar ortamında gerçekleştirildi. Tüm testler için istatistiksel anlamlılık eşiği $\mathrm{p}<0.05$ olarak belirlendi.

\section{BULGULAR}

Kontrol ve deney grubuna ait biyometrik özellikler Tablo I de verilmiştir. Yaş, boy, kilo ve vücut kitle indeksi (BMI) yönünden gruplar arasında anlamlı bir farklılığın olmadığı belirlendi.

Tablo I: Sigara İçen ve Sigara İçmeyen Bireylerin Yaş, Boy, Kilo ve BMI Değerleri (Ort \pm SD)

\begin{tabular}{|lcc|}
\hline & $\begin{array}{c}\text { Sigara İçmeyenler } \\
(\mathrm{n}=7)\end{array}$ & Sigara İçenler $(\mathrm{n}=8)$ \\
\cline { 2 - 3 } Yaş (yıl) & $33,43 \pm 4,54$ & $32,75 \pm 2,50$ \\
Boy (mt) & $1,69 \pm 0,04$ & $1,70 \pm 0,05$ \\
Kilo $(\mathrm{kg})$ & $69 \pm 6,78$ & $67,63 \pm 8,59$ \\
BMI $\left(\mathrm{kg} / \mathrm{m}^{2}\right)$ & $24,15 \pm 3,50$ & $23,64 \pm 3,18$ \\
\hline
\end{tabular}

Sigara içen ve sigara içmeyen bireylerin kontrol periyodu (30 dak.) ve deney periyoduna (60 dak.) ait açlık EGG kaydındaki normogastri, dominant frekans ve dominant güç değerleri Tablo II de verilmiştir.

Otuz dakikalık kontrol periyodu EGG kaydı analiz sonuçlarına göre; normogastri yüzdesi (sigara içenlerde 82,38 $\pm 5,63$, sigara içmeyenlerde 85,26 $\pm 5,08$ ), dominant frekans değeri (sigara içenlerde 2,75 $\pm 0,32 \mathrm{cpm}$, sigara içmeyenlerde $2,91 \pm 0,34 \mathrm{cpm}$ ) ve dominant güç değeri (sigara İçenlerde 59,04 $\pm 4,50 \mathrm{~dB}$, sigara içmeyenlerde 61,64 \pm 6,28 dB) sigara içmeyenlerin sonuçlarıyla karşılaştırıldığında sigara içenlerde her üç parametrede anlamlı olmayan bir azalma saptand.

Kronik sigara içen bireylerde akut sigara içiminin gastrik miyoelektrik aktiviteye olası etkisini test etmek amacıyla 60 dakika süren deney periyodu EGG kaydı alındı. Analiz sonuçlarına göre aktif sigara içimi normogastri yüzdesini (sigara içenlerde \%78,25 \pm 4,77, sigara içmeyenlerde $\% 83,72 \pm 4,89, \mathrm{P}<0.05$ ) ve dominant güç değerini (sigara içenlerde 55,20 \pm $3,65 \mathrm{~dB}$, sigara içmeyenlerde 60,33 $\pm 5,03 \mathrm{~dB}, \mathrm{P}$ $<0.05$ ) istatistiksel olarak önemli derecede azalttığ belirlendi $(\mathrm{P}<0.05)$. Ancak, sigara içen bireylerde dominant frekans değerindeki azalma, sigara içmeyenlere göre anlamlı bulunmadi.

Kontrol ve deney periyodunda sigara içen bireyler birbirleriyle karşılaştırıldığında aktif sigara içimi (üst üste iki sigara) her üç parametrede azalmaya neden oldu. Ancak bu azalma istatistiksel olarak anlamlı bulunmadı. 
Tablo II: Sigara İçmeyen ve Sigara İçen Bireylerin Normogastri, Dominant Frekans ve Dominant Power Değerleri (ORT $\pm \mathrm{SD})$.

\begin{tabular}{|c|c|c|c|c|}
\hline & Kontrol Periyodu (30 dak.) & & Deney Periyodu (60 dak.) & \\
\hline Parametreler & Sigara İçmeyenler (n=7) & Sigara İçenler (n=8) & Sigara İçmeyenler (n=7) & Sigara İçenler $(\mathrm{n}=8)$ \\
\hline Normogastri (\%) & $85,26 \pm 5,08$ & $82,38 \pm 5,63$ & $83,72 \pm 4,89$ & $78,25 \pm 4,77 \mathrm{a}$ \\
\hline Dominant Frekans (cpm) & $2,91 \pm 0,34$ & $2,75 \pm 0,32$ & $2,86 \pm 0,53$ & $2,64 \pm 0,25$ \\
\hline Dominant Güç (dB) & $61,64 \pm 6,28$ & $59,04 \pm 4,50$ & $60,33 \pm 5,03$ & $55,20 \pm 3,65^{a}$ \\
\hline
\end{tabular}

a Deney periyodu sigara içmeyenler ile karşılaştırıldığında $p<0,05$

\section{TARTIŞMA}

$\mathrm{Bu}$ çalışma, EGG tekniği kullanılarak sigara içiminin gastrik miyoelektrik aktiviteye etkisini incelemek için yapıldı. $\mathrm{Bu}$ çalışmanın tasarımında, çalışmaya katılan her bireyin kontrol periyodu ve deney periyodu EGG kayıtlarının aynı gün içinde ve ardışık olarak alınmasına özen gösterildi. Bu husus, sonuçların güvenilirliği açısından oldukça önemlidir. Bilindiği gibi emosyonel durum, hafif viral hastalık, gürültü sinyalleri gibi birtakım değişkenler gastrik miyoelektrik aktiviteyi etkileyebilmektedir.

Kalpte olduğu gibi mide-barsak kanalında da miyoelektrik aktivite vardır. Gastrik miyoelektrik aktivite ölçümlerinde kullanılan kutanöz elektrogastrografi tekniği ilk kez 1921 yılında Alvarez tarafından keşfedilmiş ve 1990'lı yıllarda popüler hale gelmiş girişimsel olmayan bir kayıt tekniğidir ${ }^{1}$. Elektrogastrografinin geliştirilmesi ve bu tanı yönteminin klinik uygulamada güvenilir bir araç olarak kabul edilmesi mide miyoelektrik aktivitesini değerlendiren araştırmalara büyük ilgi uyandırmıştır. Mide miyoelektrik aktivite bileşenlerinden olan ve elektrogastrogramda 24 döngü/dak ritimli gastrik yavaş dalgalar mide kasılmalarının yayılmasını ve maksimum sıklığını belirler. Antral kasılmaların oluşması yavaş dalgaların üzerinde oluşan dikensi potansiyeller ile doğrudan ilişkilidir. Mide kasılmasıyla ilişkili bu dikensi potansiyeller EGG de amplitüd artışı şeklinde yansıtılır ${ }^{1,15}$.

Mide fonksiyon bozukluğunun bazı belirti ve semptomlarının, elektrogastrografik analiz sonuçlarıyla iyi korelasyon gösterdiği bildirilmiştir ${ }^{2,16,17}$. Fonksiyonel dispepsili hastalarda mide boşalmasındaki gecikmenin, EGG kayıtlarındaki bozuk gastrik miyoelektrik aktivite ile ilişkilendirilebileceği ve gastrik miyoelektrik aktivite ile gastrik boşalma hızı arasında korelasyon olduğu gösterilmiştir ${ }^{16}$. Benzer şekilde, sağlıklı bireyler ile diyabetik gastroparetik hastalardan (D-GP) elde edilen EGG sonuçlarına göre D-GP'li bireylerin sağlıklı bireylerden rahatlıkla ve güvenli şekilde ayırt edilebileceği ve tanısının konulabileceği bildirilmiştir ${ }^{17}$. Bu konuda yapılan bir diğer çalışmada ise postprandiyal EGG kaydında gözlenen anormalliklerin gecikmiş mide boşalımının göstergesi olabileceği, ancak normal görünen her EGG kaydında mide boşaltım hızının da normal olduğu anlamına gelmeyeceği ifade edilmiştir ${ }^{15}$.

Sigara içimi veya nikotin uygulamasının gastrik motor aktiviteye etkileri konusunda insan ve hayvanlar üzerinde çok sayıda klinik ve deneysel çalışma yapılmış, bu çalışmalarda çelişkili sonuçlar elde edilmiştir ${ }^{8-13}$. Sigara içimi veya nikotin uygulamasının mide motor fonksiyonlarını yavaşlattığına dair sonuç bildiren çalışmalar çoğunluktadır 8-10,18,19. Sigara içen insanlarla yapılan iki farklı çalışmada, akut sigara içimiyle birlikte sıvı ve / veya katı gıdaların mideden geçiş hızının geciktiği gösterilmiştir ${ }^{18,19}$.

Sigara içimi veya nikotin uygulamasının mide motor fonksiyonlarına etkileri birçok çalışmada incelendiği halde sigaranın mide hareketlerini yöneten gastrik miyoelektrik aktiviteye etkileri konusunda sınırlı sayıda çalışma yapılmıştır ${ }^{14,20}$. Yapmış olduğumuz bu çalışmada, kronik sigara içenler ile kronik 
içicilerde aktif sigara içenlerin karın derisine yerleştirilen yüzeyel elektrotlarla elde ettiğimiz EGG kayıtlarında normal yavaş dalga ritminin \%'si, dominant frekans ve dominant güç parametreleri running spektral analiz yazılım programıla test edildi. Gastrik normal yavaş dalgaların (2-4 cpm) ritmik hareketlerini ifade eden normogastri yüzdesinin sigara içenlerde ve özellikle aktif sigara içen kronik içicilerde anlamlı şekilde düşük bulunması, sigaranın gastrik disritmiye sebep olduğu görüşünü kuvvetlendirmektedir. Gastrik miyoelektrik aktiviteye ait diğer bir parametre olan dominant frekans değeri, midenin EGG kaydında çoğunluklu olarak kullandığı yavaş dalga frekansıdır. Türe özgü olarak değişen bu frekans insanlarda 2-4 cpm dir. 2'den az ise bradigastri, 4'den büyük ise taşigastri olarak isimlendirilir. Araştırmamızın sonuçlarına göre sigara içimi hem kontrol periyodu hem de deney periyodunda dominant frekans parametresini anlamlı olarak etkilememiştir. Mide motilitesinin bir göstergesi olan dominant güç değerinin sigara içenlerde azaldığı gözlendi. En anlamlı azalma aktif sigara içen kronik içicilerde belirlendi. Bu yönüyle bulgularımız sigara içimi ya da nikotin uygulamasının mide motilitesini azalttığı yönünde görüş bildiren araştırmacıların sonuçlarını teyid eder niteliktedir8-10.

İnsanlar üzerinde gerçekleştirilen kontrollü bir çalışmada, sigara içen ve sigara içmeyen bireylerde transdermal nikotin bant uygulamasının (14 mg) bu bireylere ait gastrik miyoelektrik aktivitede önemli bir bozulmaya ve göç eden motor komplekslerin (MMC) periyodikliği ile açlık - tokluk motilite belirteçlerinde azalmaya neden olduğu gösterilmiştir. Aynı çalışmanın ikinci aşamasında nikotin yanıtlarında prostaglandin etkisini test etmek amacıyla, aynı bireylere aynı doz nikotin bandı uygulandıktan sonra 3 gün süreyle indometazin (150 mg/gün) verilmiş ve sigara içen bireylerde taşigastri ya da aritmi gelişmezken, sigara içmeyen bireylerde gastik miyoelektrik aktivite ritminde bozulma (disritmi) ve bulantıyla birlikte \%2 - \%16'ya varan taşigastrik durumların geliştiği bildirilmiştir. Araştırıcılar bu durumu, nikotinin sadece sigara içmeyenlerde gastrik taşiaritmileri uyardığı ve uzun süreli tütün kullanımında nikotinin disritmik etkilerine karşı gastrik yavaş dalga aktivitesini duyarsızlaştırdığı şeklinde yorumlamışlardır ${ }^{14}$. Fareler üzerinde yapılan deneysel bir çalışmada 2 ya da 6 ay sigara dumanına maruz birakılan farelerde, kolonik dismotilite geliștiği ve uzun süre sigara dumanına maruz kalan farelerde özellikle miyenterik nitrik-oksit üreten nöronlar başta olmak üzere enterik nöron sayısında önemli bir azalma olduğu gösterilmiştir ${ }^{3}$. On gönüllü bireyin (5'i sigara içen ve 5'i sigara içmeyen) gastroduodenal açlık motiliteleri incelenmiş, aktif olarak sigaranın içilmediği kontrol periyodunda sigara içenler ile sigara içmeyenler arasında herhangi bir farklılığın olmadığı, aktif sigara içilen deney periyodunda ise plazma motilin düzeyinden bağımsız olarak midede göç eden motor kompleks faz III aktivitesinin ortadan kalktığ 1 belirtilmiştir8. Faz III, mide yavaş dalga aktivitesinin düzenli, ritmik antral kasılmalarının yansıması olarak tanımlanır. Dolayısıyla, kontrol periyodu ve deney periyoduna ait bulgularımız yukarıda verilen araştırma sonuçlarıyla uyum göstermektedir. Ancak, kronik sigara içicilerde akut-aktif sigara içiminin gastrik miyoelektrik aktiviteye etkisini araştıran bir başka çalışmada, her biri $1 \mathrm{mg}$ nikotin içeren 2 adet sigaranın üst üste içiminin, postprandiyal gastrik miyoelektrik aktivitede belirgin bir değişikliğe neden olmadığı bildirilmiştir ${ }^{20}$. Bu konuda yapılmış çalışma sayısı çok az olduğundan sonuçlarımızı tüm yönleriyle karşılaştırma imkanımız bulunmamaktadır. Ancak, çalışmalarda elde edilen sonuçlar arasındaki bu farklılıkların; çalışmaya katılan katılımcıların sayı ve etnik kökenlerine, bireysel özelliklerine, açlık-tokluk 
durumuna ya da sigara alışkanlığı sürelerine bağlı olabileceğini düşünüyoruz.

Sonuç olarak bu çalışmadan elde edilen veriler, sigara içiminin gastrik miyoelektrik aktiviteyi olumsuz etkilediğini, özellikle deney periyodunda kronik içicilerde aktif sigara içiminin normogastri yüzdesini ve mide boşaltım hareketlerine kaynak oluşturan, antral kasılmaları tetikleyen dominant güç değerini anlamlı şekilde azalttığını göstermiştir. $\mathrm{Bu}$ alanda mevcut olan açığı gidermeye katkı sağlamak amacıyla, sigara içiminin gastrik miyoelektrik aktiviteye etkisiyle beraber mide hareketlerine yansımalarını da içine alan kapsamlı deneysel araştırmaların yapılması gerektiği kanaatindeyiz.

Etik Kurul Kararı: Çalışma öncesinde Dicle Üniversitesi Tıp Fakültesi Girişimsel Olmayan Klinik Araştırmalar Etik Kurulu komitesinin 03.06.2021 tarihli 303 numaralı kararı ile çalışma için etik kurul onayı alındı.

Çıkar Çatışması Beyanı: Yazarlar çıkar çatışması olmadığını bildirmişlerdir.

Finansal Destek: Bu çalışma herhangi bir fon tarafından desteklenmemiștir.

Declaration of Conflicting Interests: The authors declare that they have no conflict of interest.

Financial Disclosure: No financial support was received.

\section{KAYNAKLAR}

1. Yin J, Chen JD. Electrogastrography: methodology, validation and applications. J Neurogastroenterol Motil. 2013; 19: 5-17.

2. Gharibans AA, Coleman TP, Mousa H, et al. Spatial Patterns From High-Resolution Electrogastrography Correlate With Severity of Symptoms in Patients With Functional Dyspepsia and Gastroparesis. Clin Gastroenterol Hepatol. 2019;17: 2668-77.

3. Balasuriya GK, Mohsenipour M, Brassington K, et al. Ebselen prevents cigarette smoke-induced gastrointestinal dysfunction in mice. Clin Sci (Lond). 2020; 134: 2943-57.

4. Berkowitz L, Schultz BM, Salazar GA, et al. Impact of Cigarette Smoking on the Gastrointestinal Tract Inflammation: Opposing Effects in Crohn's Disease and Ulcerative Colitis. Front Immunol. 2018; 30: 74.

5. Ojha UC, Singh DP, Choudhari OK, et al. Correlation of Severity of Functional Gastrointestinal Disease Symptoms with that of Asthma and Chronic Obstructive Pulmonary Disease: A Multicenter Study. Int J Appl Basic Med Res. 2018; 8: 83-8.

6. Thomas GA, Rhodes J, Ingram JR. Mechanisms of disease: nicotine--a review of its actions in the context of gastrointestinal disease. Nat Clin Pract Gastroenterol Hepatol. 2005; 2: 536-44.

7. Lindell G, Farnebo LO, Chen D, et al. Acute effects of smoking during modified sham feeding in duodenal ulcer patients. An analysis of nicotine, acid secretion, gastrin, catecholamines, epidermal growth factor, prostaglandin E2, and bile acids. Scand J Gastroenterol. 1993; 28:487-94.

8. McDonnell WM, Owyang C. Effects of smoking on interdigestive gastrointestinal motility. Dig Dis Sci. 1995; 40: 2608-13.

9. Ohnishi H. Cisapride improves nicotine-evoked antral hypomotility in smokers. Kurume Med J. 1997; 44: 253-62.

10. McDonnell WM, Owyang C. Smoking markedly inhibits gastric motility in smokers and nonsmokers. Gastroenterology 1989; 96: A332.

11. Lazaar S, Boselli E, Chassard D, et al. Effect of acute cigarette smoking on gastric contents in regular smoker volunteers. A prospective randomized cross-over study. Br J Anaesth. 2015; 115: 590-4.

12. Vasavid $\mathrm{P}$, Chaiwatanarat $\mathrm{T}$, Pusuwan $\mathrm{P}$, et al. Normal Solid Gastric Emptying Values Measured by Scintigraphy Using Asian-style Meal:A Multicenter Study in Healthy Volunteers. J Neurogastroenterol Motil. 2014; 20: 371-8.

13. Sanaka M, Anjiki H, Tsutsumi H, et al. Effect of cigarette smoking on gastric emptying of solids in Japanese smokers: a crossover study using the 13Coctanoic acid breath test. J Gastroenterol 2005;40: 578-82. 
14. Kohagen KR, Kim MS, McDonnell WM, et al. Nicotine effects on prostaglandin-dependent gastric slow wave rhythmicity and antral motility in nonsmokers and smokers. Gastroenterology. 1996; 110: 3-11.

15. Chen JD, Lin Z, Pan J, et al. Abnormal gastric myoelectrical activity and delayed gastric emptying in patients with symptoms suggestive of gastroparesis. Dig Dis Sci. 1996; 41: 1538-45.

16. Zhang H, Xu X, Wang Z, et al. Correlation between gastric myoelectrical activity recorded by multichannel electrogastrography and gastric emptying in patients with functional dyspepsia. Scand J Gastroenterol. 2006; 41: 797-804.

17. Al kafee A, Okkesim Ş, Yıldırım İ, et al. Correlation analyses of Electrogastrography and Gastric
Emptying test Result. 2015 Medical Technologies National Conference (TIPTEKNO), 2015; 1-3.

18. Kadota K, Takeshima F, Inoue K, et al. Effects of smoking cessation on gastric emptying in smokers. J Clin Gastroenterol. 2010; 44: e71-5.

19. Miller G, Palmer KR, Smith B, et al. Smoking delays gastric emptying of solids. Gut. 1989; 30: 503.

20. Jonderko K, Chabińska I, Błońska-Fajfrowska B. Effect of cigarette smoking on interdigestive gastric myoelectrical activity in humans. In: Neurogastroenterology - Falk Symposium 112 (ed.: MV Singer, HJ Krammer), Kluwer Academic Publishers, Dordrecht/Boston/London 2000; 520-4. 